\title{
Impact of the systematic introduction of low-cost bubble nasal CPAP in a NICU of a developing country: a prospective pre- and post-intervention study
}

Rossano Rezzonico ${ }^{1,4}$, Letizia M Caccamo², Valeria Manfredini', Massimo Cartabia ${ }^{4}$, Nieves Sanchez ${ }^{3}$, Zoraida Paredes ${ }^{3}$, Patrizia Froesch ${ }^{5}$, Franco Cavalli ${ }^{5}$ and Maurizio Bonati ${ }^{4^{*}}$

\begin{abstract}
Background: The use of Nasal Continuous Positive Airway Pressure Ventilation (NCPAP) has begun to increase and is progressively replacing conventional mechanical ventilation (MV), becoming the cornerstone treatment for newborn respiratory distress syndrome (RDS). Howerver, NCPAP use in Lower-Middle Income Countries (LMICS) is poor. Moreover, bubble NCPAP (bNCPAP), for efficacy, cost effectiveness, and ease of use, should be the primary assistance technique employed in newborns with RDS.

Objective: To measure the impact on in-hospital newborn mortality of using a bNCPAP device as the first intervention on newborns requiring ventilatory assistance.
\end{abstract}

Methods: Design: Prospective pre-intervention and post-intervention study.

Setting: The largest Neonatal Intensive Care Unit (NICU) in Nicaragua.

Participants: In all, 230 (2006) and 383 (2008) patients were included.

Intervention: In May 2006, a strategy was introduced to promote the systematic use of bNCPAP to avoid intubation and MV in newborns requiring ventilatory assistance. Data regarding gestation, delivery, postnatal course, mortality, length of hospitalisation, and duration of ventilatory assistance were collected for infants assisted between May and December 2006, before the project began, and between May and December 2008, two years afterwards.

Outcome measures: The pre- vs post-intervention proportion of newborns who died in-hospital was the primary end point. Secondary endpoints included rate of intubation and duration of NICU stay.

Results: Significant differences were found in the rate of intubation (72 vs 39\%; $p<0.0001$ ) and the proportion of patients treated exclusively with bNCPAP (27\% vs $61 \%$; $p<0.0001$ ). Mortality rate was significantly reduced (40 vs $23 \%$; $p<0.0001$ ); however, an increase in the mean duration of NICU stay was observed (14.6 days in 2006 and 17.5 days in $2008, p=0.0481$.

The findings contribute to the evidence that NCPAP, particularly bNCPAP, is the first-line standard of care for efficacy, cost effectiveness, and ease of use in newborns with respiratory distress in LMICS.

Conclusions: This is the first extensive survey performed in a large NICU from a LMICS, proving the efficacy of the systematic use of a bNCPAP device in reducing newborn mortality. These findings are an incentive for considering bNCPAP as an elective strategy to treat newborns with respiratory insufficiency in LMICs.

\footnotetext{
* Correspondence: maurizio.bonati@marionegri.it

${ }^{4}$ Department of Public Health, Laboratory for Mother and Child Health, IRCCS

- Istituto di Ricerche Farmacologiche Mario Negri, Milan, Italy

Full list of author information is available at the end of the article
} 


\section{Article summary Article focus}

In Lower-Middle Income Countries (LMICs), a majority of the under- 5 mortality rate is due to neonatal deaths. Evidence presents the Nasal Continuous Positive Airway Pressure ventilation (NCPAP) as an effective, low-cost, and easy-to-use intervention for enhancing newborn survival.

The objective of this study was to evaluate the effects of using a bubble NCPAP (bNCPAP) device as the first intervention on mortality of newborns in the largest Neonatal Intensive Care Unit (NICU) in Nicaragua.

\section{Key messages}

- The early use of bNCPAP as the primary respiratory assistance strategy was associated with a halved mortality rate in newborns in NICUs, and positive changes in medical and nursing assistance were notable.

\section{Strengths and limitations of this study}

- This is the first wide-scale study demonstrating the efficacy of the systematic use of a low-cost bNCPAP device in a large NICU from one of the less developed countries. The study was conducted in a natural setting where clinical research and audit studies are not common, and was therefore also a practical, educational initiative.

- The main limitations were that no risk index to state the level of clinical severity of newborns could be applied and that there was a lack of both data regarding maternal socio-economic characteristics and of a thorough analysis of the medical costs.

\section{Background}

A worldwide decrease in child mortality has been achieved in the last few years, following the global attempt to pursue Millennium Development Goal 4 (MDG4) adopted at the UN Millennium Summit in 2000, targeting a 2/3 reduction in under-5 mortality by 2015 . In the last decade, however, the neonatal death rate seems to have increased from the $37 \%$ observed in 2000 to the $42 \%$ of the overall estimated child mortality recorded in 2010 [1]. Preterm birth and related complications are important leading causes of neonatal mortality.

In Lower-Middle Income Countries (LMICs), newborn deaths are dramatically prevalent, and lack of human and economical resources makes accomplishing the MDG4 challenging [2]. Among the interventions for reducing the newborn mortality rate, Nasal Continuous Positive Airway Pressure Ventilation (NCPAP) is of proven efficacy [3].
The bubble NCPAP (bNCPAP), is the simplest, low-cost respiratory support system, showing theoretical and experimental advantages, as well as similar, or greater, clinical efficacy compared to other, more sophisticated methods to deliver NCPAP (variable flow and ventilator NCPAP) [4-9].

In addition to positive experiences from Scandinavian countries [10], data published by the Neonatology Committee for the Developmental Epidemiology Network in 2000 have shown a significant inverse relationship between incidence of Bronchopulmonary Dysplasia (BPD) and use of NCPAP in very low birth weight (VLBW) newborns [11]. NCPAP therefore seems to offer an improvement compared to mechanical ventilation (MV) in this population. This was the starting point for various, important trials: Surfactant Positive Pressure and Pulse Oximetry Randomized Trial (SUPPORT) [12], Cpap Or Intubation (COIN) [13], Vermont Oxford Network (VON) [14], sURfactant and early nasal continuous Positive Airway Pressure (CURPAP) [15], Colombian Network [16], and Neocosur Network on early use of NCPAP [17]. As reviewed by W. Carlo, this "gentle ventilation", when started soon after birth, appears to reduce the need for MV and the risk of $\mathrm{BPD} /$ death, and is an alternative to the prophylactic or early surfactant approach in low, very low, and extremely low birth weight infants (ELBW) [8-10,18-22].

The use of NCPAP has begun to increase and is progressively replacing conventional MV, becoming the cornerstone treatment for newborn respiratory distress syndrome (RDS).

The statistical power of the few very interesting studies addressing NCPAP use in LMICs is poor due to the small sample sizes. All studies agree that NCPAP, particularly bNCPAP, for efficacy, cost effectiveness, and ease of use, should be the primary assistance technique employed in newborns with RDS [3,8,9,23-27].

Nicaragua is the second poorest country in Central America and in 2009 the under-5 child mortality was 27/ 1000 newborns (8/1000 in the USA), with a maternal mortality of 100/100,000 live births. Among all causes of under-5 mortality, in 2008, $45 \%$ was due to neonatal causes, of which $22 \%$ were related to prematurity, $13 \%$ to congenital anomalies, $8 \%$ to asphyxia, and $2 \%$ to sepsis [28,29].

The Bertha Calderon Hospital ( $\mathrm{BCH})$, in Managua, is the biggest maternity hospital in Nicaragua, accounting for more than 10.000 deliveries and 600 admissions in the neonatal intensive care unit (NICU) per year.

AMCA (Aiuto Medico Centro America) is a Swiss nongovernmental organisation that has been operating since 1985 [30] in Central America, particularly in Nicaragua and El Salvador. From 2005 to 2007 it set up, with the local NICU staff, a programme covering newborn resuscitation training courses, based on international guidelines 
[31], pain and $\mathrm{O}_{2}$ therapy-related risks control, and reduction in number of newborns on MV through the use of the bNCPAP device. A prospective study was thus performed in the largest NICU in Nicaragua to determine the impact of the early use of low cost bNCPAP to reduce intubation and MV and to determine its effects on mortality rate and duration of NICU stay.

\section{Methods}

This study included newborns with a history of ventilatory assistance (VA) admitted to the BCH NICU during the periods 1 May 2006 to 31 December 2006 and 1 May 2008 to 31 December 2008. During 2007, AMCA experts provided $\mathrm{BCH}$ staff with an extensive course on bNCPAP use, which was repeated thereafter by local, specifically trained staff. The impact of the intervention was therefore measured comparing the period before the project began (2006) with that two years after the project's start (2008).

The exclusion criteria were as follows: birth malformations, transfer to another hospital, suboptimal patient assistance due to lack of devices, and parental opposition to ventilation.

Data were collected from the infants' medical records by a doctor not involved in the study. Data included delivery mode (vaginal $=$ VAG or caesarean section $=C S$ ), gender $(\mathrm{M} / \mathrm{F})$, gestational age $(\mathrm{GA})$ and birth weight $(\mathrm{BW})$, main diagnosis at recovery, mean duration of NICU stay, recovery outcome, prenatal steroids, Apgar index, resuscitation measures, surfactant use, and age at start, and duration, of respiratory assistance (hours).

The study population was divided into groups: 1) those receiving only intubation and MV (MV group); 2) only bNCPAP (bNCPAP) 3) bNCPAP first, then MV (bNCPAP-MV); and 4) MV first, than bNCPAP (MVbNCPAP). The groups of patients requiring MV alone or with bNCPAP (MV, bNCPAP-MV, MV-bNCPAP) were categorised into an additional group called endotracheal tube (ETT) (Figure 1).

The institutional boards of both the $\mathrm{BCH}$ and the IRCCS - Istituto di Ricerche Farmacologiche Mario Negri, Milan, Italy approved the study. Informed consent was obtained from the parents of the infants undergoing ventilation, in accordance with established practice.

\section{Resuscitation and ventilatory assistance}

During the study, delivery room local medical staff provided resuscitation and ventilatory assistance. Newborn resuscitation was performed according to the American Academy of Pediatrics and American Heart Association guidelines [31].

No protocols or severity scores (eg. CRIB II) were defined during the study period due to lack of medical devices such as pulse oxymeters, blood gases analysers, and radiographic equipment in the delivery room [32]. The decision to start or to continue ventilatory assistance with MV or bNCPAP was based on clinical and anamnestic criteria, according to practices aimed at limiting $\mathrm{MV}$, and "the need for supplemental oxygen in newborn infants [26].

No substantial changes in delivery room assistance or medical or nursing staff were made during the study period.

bNCPAP is a highly sophisticated, fluid-dynamic system in which the bubbles produced by the expiratory water valve improve lung mechanical characteristics and minimise the respiratory system impedance $[7,12,33]$.

bNCPAP kits were provided to the NICU and included a humidifier and re-sterilisable breathing circuits (Fisher \& Paykel, New Zealand) and, to minimise infection risks, disposable nasal cannula (Hudson, USA). To further reduce costs, a dual Air/Oxygen flowmeter (Harol, Italy) was chosen as the blender, because it is much less expensive than automatic blenders and provides results of similar quality.

\section{Statistical analysis}

Microsoft Office Excel 2007 and SAS system software, release 8.2, were used for analysis. Values are presented as counts and percentages, mean \pm standard deviation, or Odd's ratios (OR) with 95\%-confidence intervals (95\% CI).

A bivariate analysis was performed to evaluate the differences observed between the two groups of ventilated patients (2006 vs 2008). For binary variables the chisquare test was used, while for continuous variables the $\mathrm{t}$-test was used.

$\mathrm{GA}$ and $\mathrm{BW}$ variables were grouped into classes and transformed from quantitative into qualitative variables. For all the statistical tests a p-value $<0.05$ was deemed significant.

A multivariate logistic regression model, with the stepwise selection option, was performed including all the following covariates assessing the death-risk determinants in VA patients: period of admission (2006 or 2008), type of ventilatory assistance (bNCPAP or ETT), sex, GA (weeks) z-score, BW (g) z-score (z-scores were used since birth weight was highly collinear with gestational age), mode of delivery, prenatal steroid, 1-minute Apgar score, 5-minute Apgar score, resuscitation, and intubation.

Lastly, the mean duration of NICU stay and of hours of MV and bNCPAP were calculated and compared with $\mathrm{t}$-tests in the two periods of interest.

\section{Results}

A total of 651 newborns made up the study population from the periods analysed (248 in 2006 and 403 in 2008). Of these, 18 (7.3\%) in 2006 and 20 (5.0\%) in 2008 $(\mathrm{p}=0.2251)$ did not fit inclusion criteria, leaving $613 \mathrm{VA}$ newborns in the study (230 in 2006 and 383 in 2008). 


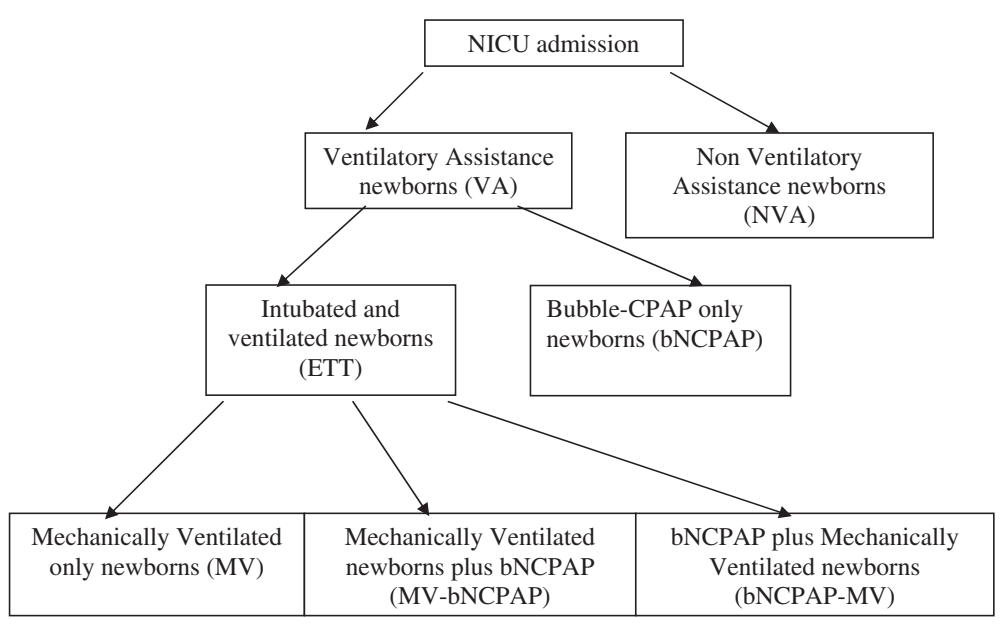

Figure 1 Flowchart showing patient distribution.

\section{VA newborn characteristics}

The characteristics of the patients from the two groups, described in Table 1, were all comparable except for a greater proportion of CS delivery patients during 2008 (53\% in 2006 and 69\% in 2008, p =0.0001). No patients received surfactant treatment. In 2008 a lower proportion of VA patients received resuscitation (54\% in 2006 vs $39 \%$ in 2008, $\mathrm{p}=0.0006$ ). The 1 st and 5th minute Apgar indices were comparable in newborns who received resuscitation at birth (RES). A higher proportion of patients required intubation at birth in 2006 $(p=0.0410)$. No differences were observed in rate of steroid prophylaxis use.

NICU admission diagnoses, despite the aforementioned limitations, were comparable in 2006 and 2008 (Table 2).

\section{Ventilatory assistance mode}

In 2006 the MV patient prevalence was $50 \%$ and decreased to $10 \%$ in 2008 ( $\mathrm{p}<0.0001$ ). During the two periods, no differences were found in the proportion of MV-bNCPAP patients $(\mathrm{p}=0.5467)$, while a significant increase from $15 \%$ to $23 \%(\mathrm{p}=0.0202)$ was found in the bNCPAP-MV group. The rate of ETT patients was $72 \%$ in 2006 and decreased to $39 \%$ in 2008 ( $\mathrm{p}<0.0001)$.

The introduction of bNCPAP led to an increase newborns treated with this device, from $28 \%$ in 2006 to $61 \%$ in 2008 ( $\mathrm{p}<0.0001)$, consistent with the decrease in ETT patients (Figure 2).

In $2008,54 \%$ of the bNCPAP newborns started treatment at birth, $74 \%$ within the first, and $86 \%$ within the second hour of life.

\section{Mortality}

In 2008 the number of VA patients admitted to the NICU increased by $67 \%$, but mortality decreased significantly, from $40.4 \%(\mathrm{n}=93)$ in 2006 to $22.7 \%(\mathrm{n}=87)(\mathrm{p}<0.0001)$. In ETT newborns, the mortality rate remained unchanged, from $53.0 \%$ to $53.3 \%(\mathrm{p}=\mathrm{ns}$ ) (Figure 3). If only the MV patient group was considered, however, mortality increased from $52 \%$ in 2006 to $90 \%$ in 2008 ( $<<0.0001)$ (Table 3).

In the bNCPAP group deaths decreased from $7.8 \%$ in 2006 to $3.0 \%$ in 2008 , but the small number of cases does not permit statistical analyses.

In VA newborns who died in 2008, however, significantly lower mean GA (30.7 vs 32.5 weeks) and BW $(1,383$ g vs $1,633 \mathrm{~g})$ were observed compared to 2006 (Table 3).

Finally, during the two periods analysed, the stepwise logistical regression model applied to the mortality-related risk factors revealed two important inverse relationships. The first was between the probability of death and the 5 -minute Apgar score $(\mathrm{OR}=0.68, \mathrm{p}$-value $<0.0001)$ and the second was between the probability of death and GA $(\mathrm{OR}=0.34$, p-value $<0.0001)$. Furthermore, the model revealed that ventilation with bNCPAP decreased the risk of death compared to intubation and mechanical ventilation (ETT) $(\mathrm{OR}=0.04$, $\mathrm{p}$ value $<0.0001)$, as reported in Table 4 .

\section{NICU duration of stay and ventilation mode distribution}

An increase in the mean duration of NICU stay was observed in VA patients: 14.6 days in 2006 and 17.5 days in $2008(\mathrm{p}=0.0481)$ (Table 5).

In all VA groups, the mean number of hours of the two types of assistance given (MV and bNCPAP) were calculated separately, including those of children receiving bNCPAP-MV and MV-bNCPAP. As shown in Table 5 all values were comparable during the two periods.

The overall number of MV and BNCPAP hours was calculated in the two study periods, showing a $209.6 \%$ increase in the overall bNCPAP hours in 2008 compared 
Table 1 Characteristics of the newborns with ventilatory assistance (VA)

\begin{tabular}{|c|c|c|c|c|c|}
\hline & 2006 & & 2008 & & $p$ \\
\hline VA patients N (\%) & 230 & $(74.7)$ & 383 & $(81.3)$ & 0.0269 \\
\hline Sex $M / F$ ratio & $142 / 88$ & 1.61 & $238 / 145$ & 1.64 & ns \\
\hline CS/NAG ratio & $121 / 109$ & 1.11 & $261 / 119$ & 2.19 & $<0.0001$ \\
\hline Prenatal steroids N (\%) & 73 & (33.6) & 119 & (31.6) & ns \\
\hline GA weeks, $N$ mean $\pm[S D]$ & 216 & $34.3 \pm[3.9]$ & 379 & $34.4 \pm[3.8]$ & ns \\
\hline$<27 \mathrm{~N}(\%)$ & 8 & $(3.7)$ & 18 & $(4.7)$ & ns \\
\hline $28-33 \mathrm{~N}(\%)$ & 73 & (33.8) & 112 & $(29.6)$ & ns \\
\hline $34-36$ N (\%) & 70 & $(32.4)$ & 135 & (35.6) & ns \\
\hline $37-42 \mathrm{~N}(\%)$ & 63 & $(29.2)$ & 114 & $(30.1)$ & ns \\
\hline$>42 \mathrm{~N}(\%)$ & 2 & $(0.9)$ & - & - & ns \\
\hline BW g, N mean $\pm[S D]$ & 217 & $1975 \pm[792]$ & 377 & $2001 \pm[766]$ & ns \\
\hline ELBW N (\%) & 14 & $(6.5)$ & 38 & $(10.1)$ & ns \\
\hline VLBW N (\%) & 58 & $(26.7)$ & 73 & $(19.4)$ & 0.0371 \\
\hline LBW N (\%) & 87 & $(40.1)$ & 161 & $(42.7)$ & ns \\
\hline NBW N (\%) & 58 & $(26.7)$ & 105 & $(27.9)$ & ns \\
\hline RES NA & $116 / 216$ & $(53.7)$ & $147 / 376$ & $(39.1)$ & 0.0006 \\
\hline 1-minute Apgar RES N, mean + [SD] & 116 & $5.1 \pm[2.4]$ & 144 & $5.5 \pm[2.2]$ & ns \\
\hline 5-minute Apgar RES N, mean $+[S D]$ & 116 & $6.9 \pm[2.5]$ & 144 & $7.2 \pm[2.1]$ & ns \\
\hline Intubated at birth / RES (\%) & $29 / 116$ & $(25.0)$ & $22 / 147$ & $(15.0)$ & 0.0410 \\
\hline Death N (\%) & 93 & $(40.4)$ & 87 & $(22.7)$ & $<0.0001$ \\
\hline
\end{tabular}

CS Caesarean section delivery.

VAG Vaginal delivery.

RES Newborns resuscitated at birth.

to 2006, due to the increase in bNCPAP newborns (Table 5).

\section{Discussion}

In this study the interventions proposed resulted in decreased rates of intubation and mechanically ventilated newborns (72 vs 39\%; $\mathrm{p}=0.0001$ ) and in a proportionally larger number of patients treated exclusively with bNCPAP (27\% vs 61\%; $\mathrm{p}=<0.0001)$. Mortality rate was significantly reduced (40.4 vs $22.7 \%$; $\mathrm{p}=0.0001)$. The average length of NICU stay in VA patients increased in 2008

Table 2 Comparison of recovery diagnoses

\begin{tabular}{lllll}
\hline Diagnoses & $\mathbf{2 0 0 6}(\mathbf{N})$ & $\mathbf{2 0 0 8}(\mathbf{N})$ & $\mathbf{2 0 0 6}(\mathbf{\%})$ & $\mathbf{2 0 0 8}(\mathbf{\%})$ \\
\hline Unknown & 6 & 10 & 2.6 & 2.6 \\
Apnoea & 8 & 14 & 3.5 & 3.7 \\
Asphyxia & 13 & 19 & 5.7 & 5.0 \\
Seizure & 2 & 3 & 0.9 & 0.8 \\
RDS & 185 & 311 & 80.4 & 81.2 \\
Sepsis and shock & 15 & 26 & 6.5 & 6.8 \\
Polycythaemia & 1 & 0 & 0.4 & 0 \\
Total & 230 & 383 & 100 & 100 \\
\hline
\end{tabular}

RDS includes: pulmonary bleeding, congenital pneumonia, prematurity RDS, MAS, transient neonatal tachypnoea, pulmonary emphysema. to 2.9 days. There was a large increase in overall number of hours of bNCPAP (209\%) in 2008 compared to 2006.

\section{Characteristics of the VA newborns}

The $\mathrm{BCH}$ is the national referral centre for pathologic pregnancies. During the two periods, the characteristics of all VA patients were similar. The higher 2008 CS rate may be explained by a generally more prudent attitude towards term and preterm delivery during recent years [34,35] rather than by greater severity of cases in 2008. The relative increase in CS percentage is also likely due to hospital characteristics. Conversely, the decreased rate of newborns requiring resuscitation (54\% in 2006 and 39\% in 2008) and intubation at birth (25\% in 2006 and $15 \%$ in 2008) may be related to the greater number of CS in 2008. It was not possible to apply a risk index [32], but no differences emerged between 2006 and 2008 in Apgar indeces in resuscitated newborns, supporting comparable clinical conditions in the two groups. Consistent with this hypothesis, the multivariate analysis showed no influence of delivery mode and newborn resuscitation on mortality. The association between death risk and Apgar score at 5 minutes, however, is well documented in the literature [36].

Steroid prophylaxis against RDS was the only available prenatal care index and was comparable in the two 


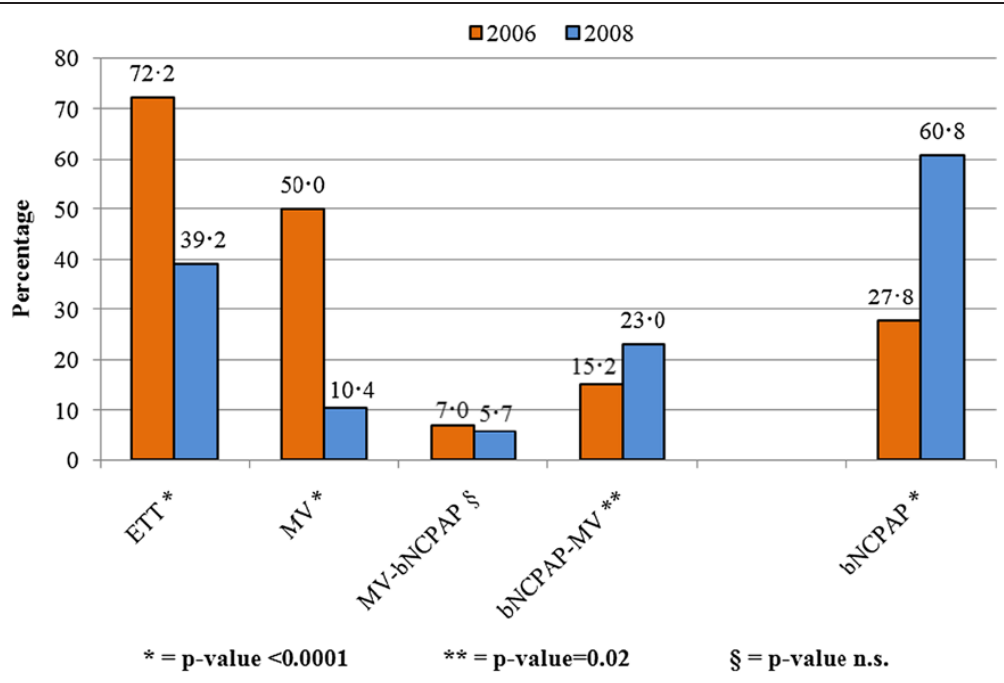

Figure 2 Ventilatory assistance newborns and ventilation type.

periods. The lack of data on other prenatal care and maternal socio-economic characteristics (instruction, wealth, parity, age, income, etc.) may be a limitation of this study. A change in prenatal care and maternal socio-economic conditions, however, is unlikely given the short study period. No differences were found between 2006 and 2008 in terms of mean GA and BW, GA, MV, and 5-minute Apgar score emerged as the most relevant factors in determining the outcome of all VA newborns.

\section{Ventilation mode and mortality}

In this study it was not possible to evaluate MV-related lung damage, such as BPD $[12,18,19]$, but only intubation and MV impact on mortality rate.

Multivariate analysis for the most influential deathrelated risk factors shows MV as one of the only three relevant variables.
In the ETT group of patients, mortality rate remained unchanged (53\%), but the percentage of ETT patients decreased from $72 \%$ in 2006 to $39 \%$ during 2008, leading to a consistent reduction in the overall mortality (Figure 3 ). In the MV patient group, the death rate increased from $59 \%$ to $90 \%$, with no impact on the overall mortality, due to the concurrent decrease in number of newborns in this group (from $50 \%$ to $10 \%$ ).

Such high mortality rates in ventilated newborns can be explained both by the fact that the more compromised newborns received MV more frequently and by the lack of surfactant therapy.

In the groups of MV-bNCPAP patients, BNCPAP was applied after MV to stabilise patients and to avoid reintubation [4], and the rate remained very small $(6 \%$ of all VA newborns) during the periods examined, with no influence on mortality.

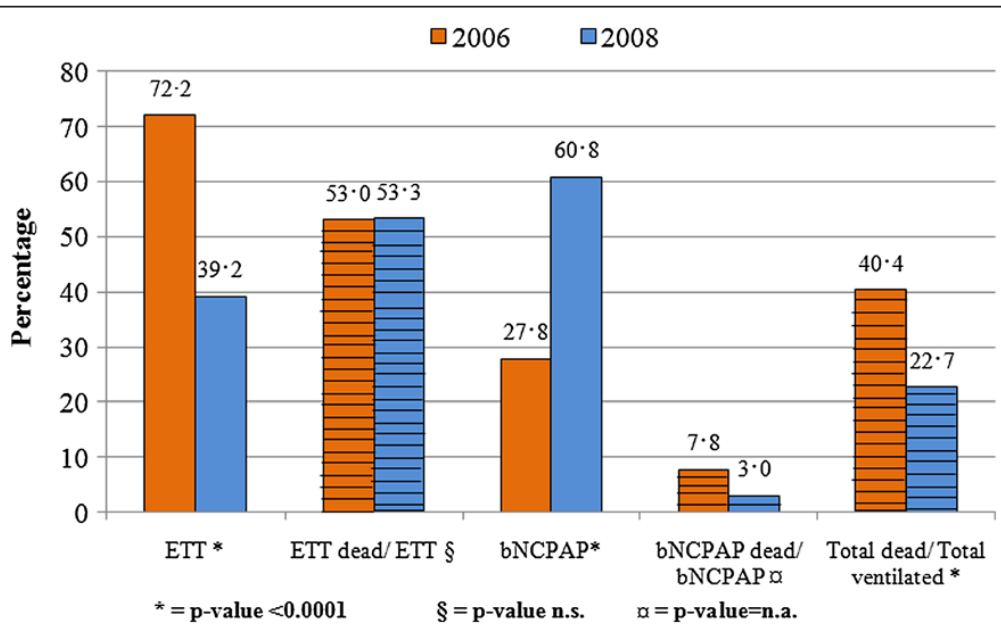

Figure 3 Distribution by ventilation type and related deaths (striped). 
Table 3 Mortality rate distribution

\begin{tabular}{|c|c|c|c|c|c|}
\hline & 2006 & & 2008 & & $\mathrm{p}$ \\
\hline Deaths VA & $93 / 230$ & $(40.4)$ & $87 / 383$ & $(22.7)$ & $<0.0001$ \\
\hline Deaths ETT & $88 / 166$ & $(53.0)$ & $80 / 150$ & $(53.3)$ & ns \\
\hline Deaths MV & $60 / 115$ & $(52.2)$ & $36 / 40$ & $(90.0)$ & $<0.0001$ \\
\hline Deaths MV-NCPAP & $7 / 16$ & $(43.7)$ & $1 / 22$ & $(4.5)$ & 0.0054 \\
\hline Deaths NCPAP-MV & $21 / 35$ & $(60.0)$ & $43 / 88$ & $(43.9)$ & ns \\
\hline Deaths NCPAP & $5 / 64$ & $(7.8)$ & $7 / 233$ & (3.0) & ns \\
\hline GA in VA deaths, N, mean $\pm[S D]$ & 91 & $32.5 \pm[4.2]$ & 87 & $30.7 \pm[4.1]$ & 0.0043 \\
\hline BW in VA deaths, $N$, mean $\pm[S D]$ & 92 & $1633 \pm[774.7]$ & 87 & $1383 \pm[656.6]$ & 0.0213 \\
\hline
\end{tabular}

Patients failing to respond to the bNCPAP in either period were switched to MV (bNCPAP-MV group). Since the use of bNCPAP was systematically encouraged during 2008, a consistent increase in failure incidence (15\% vs $23 \% \mathrm{p}=0.02$ ) in this group was conceivable. However, the bNCPAP failure rate in the bNCPAP-MV group was limited and comparable with literature data $[37,38]$. As shown in Table 4 the mortality rate in this group didn't change in the two periods. This is a clinically relevant point, since an inappropriate delay in MV is known to compromise its efficacy and the patient's clinical outcome.

All these considerations seem to support an appropriate application of both ventilation methodologies during 2008.

The high success of the non-invasive respiratory support was also associated with its early application [12,19], as $54 \%$ of the patients started at birth and $86 \%$ within the first two hours of life. Moreover, the mean GA of newborns who died during 2008 was two weeks less than that observed in 2006, further supporting the improvement in assistance quality level.

\section{Duration of NICU admission and distribution of ventilation type}

Mean duration of NICU stay increased by 2.9 days during 2008 in newborns from the VA group (Table 3).

Non-respiratory impairment, infection complications, nutritional factors, and preterm birth-related complications generate complexity in assistance and can increase duration of NICU stay. Despite the increase in number of VA newborns in 2008, the ETT group decreased from $72 \%$ to $39 \%$ in 2008 , representing nearly an equivalent number

Table 4 Logistic regression model for death risk and variables considered

\begin{tabular}{llll}
\hline & OR & $\mathbf{9 5 \%} \mathbf{C l}$ & $\mathbf{p}$ \\
\hline bNCPAP vs ETT & 0.04 & $(0.02-0.08)$ & $<0.0001$ \\
GA z-score & 0.34 & $(0.26-0.44)$ & $<0.0001$ \\
Apgar score at 5 minutes & 0.68 & $(0.59-0.79)$ & $<0.0001$ \\
\hline
\end{tabular}

GA z-score z score of gestational age. of newborns. For this reason, the total hours of MV for the ETT group increased by only $7.6 \%$ (Table 3 ). Recent data have shown that the rate of serious adverse events related to $\mathrm{MV}$ (e.g. accidental disconnection from the respiratory circuit or unintentional removal or obstruction of the tracheal tube) is proportional to the nursing workload [39]. Assistance shifted to the bNCPAP patients, accounting for a 209\% increase in the overall amount of bNCPAP hours of assistance compared to 2006. The improved survival that was observed was significant, but also let to an increase in the workload in caring for patients with bNCPAP, given the greater need for nursing staff time and expertise. A change in clinical practices therefore occurred, with an improvement in quality of care. The reduced need for MV leads to a reduction in use of resources, and this is especially important in settings with resource limitations.

\section{NCPAP in LMICs}

Few studies evaluating NCPAP use in LMICs exist. Urs and colleagues, in a prospective observational study, obtained an $80 \%$ success rate using bNCPAP in 50 Indian preterms (28-37 weeks GA), supporting the primary use of the bNCPAP in poorer countries [40]. In a retrospective descriptive analysis from Zimbabwe, data from 234 newborns $(1,730 \mathrm{~g}$ mean $\mathrm{BW})$ with a death rate incidence of

Table 5 Distribution of NICU stay and duration of ventilation

\begin{tabular}{|c|c|c|c|c|c|}
\hline & \multicolumn{2}{|c|}{2006} & \multicolumn{2}{|c|}{2008} & \multirow[t]{2}{*}{$p$} \\
\hline & $\overline{\mathrm{N}}$ & Mean $\pm[S D]$ & $\bar{N}$ & Mean $\pm[S D]$ & \\
\hline \multicolumn{6}{|l|}{ Days in NICU } \\
\hline VA patients & 218 & $14.6 \pm[16.2]$ & 376 & $17.5 \pm[19.9]$ & 0.0481 \\
\hline EET group & 159 & $14.4 \pm[16.9]$ & 148 & $18.9 \pm[22.3]$ & ns \\
\hline bNCPAP group & 59 & $15.1 \pm[14.6]$ & 228 & $16.9 \pm[18.2]$ & ns \\
\hline \multicolumn{6}{|l|}{ Hours of MV } \\
\hline EET group & 158 & $101.6 \pm[113.6]$ & 149 & $115.9 \pm[113.9]$ & ns \\
\hline \multicolumn{6}{|l|}{ Hours of bNCPAP } \\
\hline All bNCPAP groups & 110 & $49.8 \pm[46.7]$ & 336 & $50.5 \pm[69.5]$ & ns \\
\hline
\end{tabular}


46. $4 \%$ were analysed to compare MV with NCPAP respiratory support. MV resulted as the only variable associated with a significant increase in death risk when compared to NCPAP [24].

In extreme conditions, the lack of resources leads to restrictive criteria for access to NICUs. In South Africa, Piepier and colleagues found that, in 21 VLBW newborns who were not admitted to the NICU, the introduction of NCPAP support led to a significant reduction in mortality rate, without severe complications. The authors also found that, given the simplicity of the method, it could be provided by trained nurses even in VLBW infants [23]. The safety and efficacy of bNCPAP, applied by trained nurses for reducing $\mathrm{MV}$, was confirmed by Koyamaibole [27]. A recent Indian RCT comparing bNCPAP with ventilator NCPAP found greater success, and comparable safety, in managing preterm neonates with early onset respiratory distress with the first method [8]. Despite the fact that surfactant was listed as an essential drug by the World Health Organisation, its use in resource limited settings is a matter of debate [41]. Its cost is unaffordable for the health economy of most developing countries, including Nicaragua, and bNCPAP is an affordable and determining strategy for reducing MV and the need for surfactant therapy. The extremely low availability of surfactant is unacceptable and makes the present study somewhat comparable to the first CPAP studies, in which surfactant was not available.

Despite the fact that the published studies had limited statistical power due to their small population sizes, the accumulated evidence $[3,8,9,23-27,40-42]$ is enough to consider NCPAP, particularly bNCPAP, as the first-line standard of care for efficacy, cost effectiveness, and ease of use in newborns with respiratory distress in LMICs [43].

\section{Conclusions}

This is the first study to be performed in a large NICU from a developing country. It demonstrates an association between the systematic use of a low-cost bNCPAP device and a reduction in mortality and strongly supports the early use of bNCPAP as the primary respiratory assistance strategy when mechanical ventilation is needed.

The proportion of bNCPAP newborns reached 61\% and mortality decreased to $22 \%$ in 2008 , with no significant differences in the populations from the two time periods. Economic data were missing, but, as in other LMICs with restricted health resources and high neonatal mortality rates, Nicaragua has limited NICU facilities. The implementation of a low-cost bNCPAP strategy represents an adequate system for avoiding invasive procedures, containing the need for sophisticated technologies, and reducing economic pressure.

\section{Ethics approval}

Institutional Review Board of the Bertha Calderon Hospital, Managua, Nicaragua and of the IRCCS - Istituto di Ricerche Farmacologiche Mario Negri, Milan, Italy.

\section{Competing interests}

The authors declare that they have no competing interests.

\section{Authors' contributions}

RR and LC conceived the study, wrote the study protocol and trained the medical staff in the Bertha Calderon Hospital. RR with MB wrote the first draft of the manuscript. NS supervised clinical work in Managua and SP collected data in the Bertha Calderon Hospital. MC did the statistical analyses. VM gave an important contribution to writing the paper. MB defined and supervised the analyses. PF and FC, as past presidents of AMCA, coordinated the contacts between Switzerland and Nicaragua. All investigators reviewed and contributed to the manuscript. All authors read and approved the final manuscript.

\section{Acknowledgements}

The authors acknowledge the Bertha Calderon NICU nursing and medical staff for the incredible daily clinical work in difficult conditions. We thank Nicolette Gianella and Manuela Cattaneo for coordinating the project in Nicaragua and in Switzerland. Chiara Pandolfini, Rita Campi, Filomena Fortinguerra, and Antonio Clavenna from the Department of Public Health of the Mario Negri Institute provided support to the authors.

\section{Data sharing statement}

Access to the study data may be provided by the authors to other researchers upon request.

\section{Funding}

The study was funded by a private donation collected by AMCA, a Swiss non-profit association for international cooperation and development.

\section{Author details}

${ }^{1}$ NICU Rho Az. Ospedaliera "G. Salvini" Garbagnate Milanese, Milan, Italy. ${ }^{2}$ Az. Ospedaliera Universitaria L. Meyer, Florence, Italy. ${ }^{3}$ UCIN Hospital Bertha Calderon Managua, Managua, Nicaragua. ${ }^{4}$ Department of Public Health, Laboratory for Mother and Child Health, IRCCS - Istituto di Ricerche Farmacologiche Mario Negri, Milan, Italy. ${ }^{5}$ AMCA, Aiuto Medico Centro America, Giubiasco, Switzerland.

Received: 15 May 2014 Accepted: 24 February 2015 Published online: 25 March 2015

\section{References}

1. Lawn YE, Gravett MG, Nunes TM, Rubens CE, Stanton C, and the GAPPS Review Group. Global report on preterm birth and stillbirth (1 of 7): definitions description of burden and opportunities to improve data. BMC Pregnancy Childbirth. 2010;10 Suppl 1:S1.

2. Lozano R, Wang H, Foreman KJ, Rajaratnam JK, Naghavi M, Marcus JR, et al. Progress towards Millenium Development Goals 4 and 5 on maternal and child mortality: an updated systematic analysis. Lancet. 2011;378:1139-65.

3. Barros FC, Bhutta ZA, Batra M, Hansen TN, Victora CG, Rubens CE, et al. Global report on preterm birth and stillbirth (3 of 7) evidence for effectiveness of interventions. BMC Pregnancy Childbirth. 2010;10(Suppl):S3.

4. Gupta S, Sinha K, Tin W, Donn SM. A randomized controlled trial of post-extubation bubble continuous positive airway pressure versus infant flow drive continuous positive airway pressure in preterm infants with respiratory distress syndrome. J Pediatr. 2009;154:645-50.

5. Bubble PRA, CPAP. A clash of science, culture, and religion. J Pediatr. 2009;154:633-4.

6. Yagui AC, Vale LA, Haddad LB, Prado C, Rossi FS, Deutsch AD, et al. Bubble CPAP versus CPAP with variable flow in newborns with respiratory distress: a randomized controlled trial. J Pediatr (Rio J). 2011;87:499-504.

7. Manilal-Reddy PI, Al-Jumaily AM. Understanding the use of continuous oscillating positive airway pressure (bubble CPAP) to treat neonatal respiratory disease: an engineering approach. J Med Eng Technol. 2009;33:214-22. 
8. Tagare A, Kadam S, Vaidya U, Pandit A, Patole S. Bubble CPAP versus ventilator CPAP in preterm neonates with early onset respiratory distresss. A randomized controlled trial. J Trop Pediatr. 2013;59:113-9.

9. Carlo WA. Gentle ventilation: the new evidence from the SUPPORT, COIN, VON, CURPAP, Colombian Network and Neocosur Network trials. Early Human Dev. 2012;88S2:S81-3.

10. Verder H. Nasal CPAP has became an indispensable part of the primary treatment of newborns with respiratory distress syndrome. Acta Pediatrica. 2007;96:482-4

11. Van Marter $\sqcup$, Allred EN, Pagano M, Sanocka U, Parad R, Moore M, et al. Do clinical markers of barotrauma and oxygen toxicity explain interhospital variation in rates of chronic lung disease? Pediatrics. 2000;105:1194-201.

12. SUPPORT Study Group of the Eunice Kennedy Shriver NICHD Neonatal Research Network, Finer NN, Carlo WA, Walsh MC, Rich W, Gantz MG, et al. Early CPAP versus surfactant in extremely preterm infants. N Engl J Med. 2010;362(21):1970-9.

13. Morley CJ, Davis PG, Doyle LW, Brion LP, Hascoet JM, Carlin JB. Nasal CPAP or intubation at birth for very preterm infants. N Engl J Med. 2008;358:700-8.

14. Dunn MS, Kaempf J, de Klerk A, de Klerk R, Reilly M, Howard D, et al. Randomized trial comparing 3 approaches to the initial respiratory management of preterm neonates. Pediatrics. 2011;128:e1069-76.

15. Sandri F, Plavka R, Ancora G, Simeoni U, Stranak Z, Martinelli S, et al. Prophylactic or early selective surfactant combined with nCPAP in very preterm infants. Pediatrics. 2010;125(6):e1402-9.

16. Rojas MA, Lozano JM, Rojas MX, Laughon M, Bose CL, Rondon MA, et al. Very early surfactant without mandatory ventilation in premature infants treated with early continuous positive airway pressure: a randomized, controlled trial. Pediatrics. 2009;123:137-42.

17. Tapia JL, Urzua S, Bancalari A, Meritano J, Torres G, Fabres J, et al. Randomized trial of early bubble continuous positive airway pressure for very low birth weight infants. J Pediatr. 2012;161:75-80. e1.

18. Aly H. Ventilation without tracheal intubation. Pediatrics. 2009;124:786-8.

19. Narendran V, Donovan EF, Hoath SB, Akinbi HT, Steichen JJ, Jobe AH. Early bubble CPAP and outcomes in ELBW preterm infants. J Perinatol. 2003;23:195-9.

20. Miller NE. Techniques of early respiratory management of very low and extremely low birth weight infants. Neonatal Network. 2010;29:153-60.

21. Sekar KC, Corf KE. To tube or not to tube babies with respiratory syndrome. J Perinatol. 2009;29:568-72.

22. Nowadzky T, Pantoja A, Britton JR. Bubble continuous positive airway pressure, a potentially better practice, reduces the use of mechanical ventilation among very low birth infants with respiratory distress syndrome. Pediatrics. 2011;123:1534-9.

23. Piepier $\mathrm{CH}$, Smith J, Maree D, Pohl FC. Is NCPAP of value in extreme preterms with no access to neonatal intensive care? J Trop Pediatr. 2003:49:148-52.

24. Kambarami R, Chidede O, Chirisa M. Neonatal intensive care in a developing country: outcome and factors associated with mortality. Cent Afr J Med. 2000;46(8):205-7.

25. Upadhyay A, Deorari AK. Continuous positive airway pressure - a gentler approach to ventilation. Indian Pediatr. 2004;41:459-69.

26. Levesque BM, Kalish LA, LaPierre J, Welch M, Porter V. Impact of implementing 5 potentially better respiratory practices on neonatal outcomes and costs. Pediatrics. 2011;128:e218-26.

27. Koyamaibole L, Kado J, Qovu JD, Colquhoun S, Duke T. An evaluation of bubble-CPAP in a neonatal unit in a developing country: effective respiratory support that can be applied by nurses. J Trop Pediatr. 2005;52:249-53.

28. WHO Mortality Data. http://www.who.int/healthinfo/statistics/LT_method.pdf (accessed March 25, 2015).

29. Pan American Health Organization. Health System Profile in Nicaragua: Monitoring and Analyzing Health System Change/Reform. 3rd ed. Washington, DC: PAHO; 2009

30. Masera G, Baez F, Biondi A, Cavalli F, Conter V, Flores A, et al. North-south twining in paediatric-oncology: the La Mascota programme. Nicaragua Lancet. 1998;352:1923-6.

31. Textbook of Neonatal Resuscitation of the American Heart Association and the American Academy of Pediatrics. Fifth editions 2006.

32. Dorling JS, Field DJ, Maktelow B. Neonatal disease severity scoring systems, Arch Dis Child Fetal Neonatal Ed. 2005;90:F11-6.
33. Pillow JJ, Hillman N, Moss TJ, Polglase G, Bold G, Beaumont C, et al. Bubble continuous positive airway pressure enhances lung volume and gas exchange in preterm lambs. Am J Resp Crit Care Med. 2007;176:63-7.

34. Gabriel R, Grolier F, Graesslin O. Can obstetric care provide further improvement in the outcome of preterm infants? Eur J Obstet Gynecol Reprod Biol. 2004;117 Suppl 1:S25-8.

35. Zhang J, Troendle J, Reddy UM, Laughon SK, Branch DW, Burkman R, et al. Consortium on safe labor. Contemporary Cesarean delivery practice in the United States. Am J Obstet Gynecol. 2010;203(4):326.e1-326.e10.

36. Niodromiti S, Mackay DF, Smith GCS JP, Nelson SM. Apgar score and the risk of cause-specific infant mortality: a population-based cohort study. Lancet. 2014;384(9956):1749-55.

37. Meneses J, Bhandari V, Alves JG, Herrmann D. Non invasive ventilation for respiratory distress syndrome: a randomized controlled trial. Pediatrics. 2011:127(2):300-7.

38. Ammari A, Suri M, Milisavljevic V, Sahni R, Bateman D, Sanocka U, et al. Variables associated with the early failure of nasal CPAP I very low birth weight infants. J Pediatr. 2005;147:341-7.

39. Lamy Filho F, Silva AA, Lopes JM, Lamy ZC, Simões VM, Dos Santos AM. Staff workload and adverse events during mechanical ventilation in neonatal intensive care units. J Pediatr (Rio J). 2011;87(6):487-92.

40. Urs SP, Khan F, Maiya PP. A primary respiratory support for respiratory distress syndrome in newborns. Indian Pediatr. 2009;46:409-11.

41. Vidyasagar D, Velaphi S, Bhat V. Surfactant replacement therapy in developing countries. Neonatology. 2011;99:355-66.

42. Martin S, Duke T, Davis P. Efficacy and safety of bubble CPAP in neonatal care in low and middle income countries: a systematic review. Arch Dis Child Fetal Neonatal Ed. 2014;99(6):F495-504.

43. Jensen EA, DeMauro SB, Kirpalani H. Has enough evidence accumulated to consider CPAP a first-line standard of care in developing countries? Arch Dis Child Fetal Neonatal Ed. 2014;99:F443-4.

\section{Submit your next manuscript to BioMed Central and take full advantage of:}

- Convenient online submission

- Thorough peer review

- No space constraints or color figure charges

- Immediate publication on acceptance

- Inclusion in PubMed, CAS, Scopus and Google Scholar

- Research which is freely available for redistribution

Submit your manuscript at www.biomedcentral.com/submit
C) Biomed Central 